DOI: 10.12957/demetra.2015.14464

\title{
Reflexões sobre a lógica do consumo e sua influência na construção dos múltiplos sentidos do corpo na complexidade da metrópole
}

\section{Reflections on the logic of consumption and its influence on the construction of multiple senses of the body in the complexity of the metropolis}

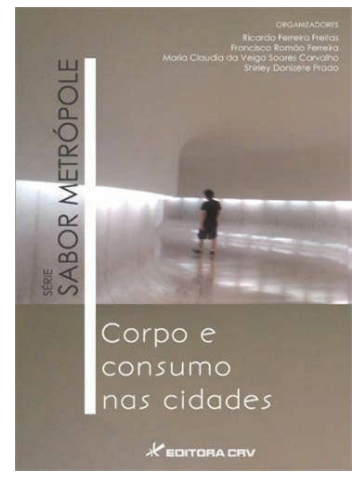

CORPO E CONSUMO NAS CIDADES

Coleção: SABOR METROPOLE

Maria Claudia da Veiga Soares

Carvalho, Francisco Romão Ferreira,

Shirley Donizete Prado,

Ricardo Ferreira Freitas.

Rio de Janeiro: Ed. CRV, 2014. 278p.

ISBN: 8580429978

Daniela Menezes Neiva Barcellos'

1 Universidade do Estado do Rio de Janeiro, Instituto de Nutrição, Programa de PósGraduação em Alimentação, Nutrição e Saúde. Núcleo de Estudos sobre Cultura e Alimentação.

Correspondência / Correspondence

Daniela Menezes Neiva Barcellos

E-mail: danimneiva@hotmail.com
A metrópole hoje é um espaço de emoções e excessos, e os corpos que nela transitam são cheios de marcas, contornos e significados, sendo expressão do diálogo contínuo que produzem com as cidades. O imaginário urbano do nosso século, habitado por medos das mais variadas ordens, fomenta o crescimento das dietas, do mercado das apólices de seguros, das academias de ginástica e tudo mais que oferece proteção e vigilância. Fechamo-nos em bunkers. É um controle que protege e encontra apoio nas mídias contemporâneas, sempre prontas a oferecer saídas imediatas, formatadas e assépticas, mesmo que instituindo paradoxos como pavor e alegria, desterritorialização e pertencimento, juventude e próteses, fartura e carência, e que perpassam o consumo como solução que preenche, dita e conforta a rotina cotidiana.

Nesse cenário urbano contemporâneo, identidades vão sendo construídas e o consumo é um meio de alcançar os modelos idealizados pelas mídias. Inseridos nesse panorama, os movimentos dos corpos e as diferentes lógicas de consumo nas cidades contemporâneas fazem parte do livro Corpo e consumo nas cidades, segundo volume da Série Sabor Metrópole, uma coletânea organizada pelos professores Ricardo Ferreira Freitas, Francisco Romão Ferreira, Maria Claudia da Veiga Soares Carvalho e Shirley Donizete Prado, que reúne pesquisadores de Comunicação Social, Ciências Sociais e Alimentação e Nutrição, para discutir o consumo como elemento comunicacional. 
Os capítulos tratam de questões inquietantes sobre o consumo na atualidade e estão divididos em três partes que dialogam entre si. A primeira, "Corpo, comunicação e estéticas contemporâneas"; a segunda, "Comunicação, cidade e consumo", e a terceira, "Comunicação, consumo e cultura”. Os artigos circulam sobre temáticas que envolvem alimentação, corpo, saúde, habitação, segurança, violência, qualidade de vida, meio ambiente, comunicação e cultura.

Na parte I, "Corpo, comunicação e estéticas contemporâneas", o primeiro capítulo do livro, "Culturas do consumo, corporalidades e urbanidade como tecidos contemporâneos", das autoras Rose de Melo Rocha e Tânia Hoff, traz como ideia central o consumo como fenômeno sociocultural de grande complexidade, por problematizar suas práticas na dimensão material e simbólica e, assim, possibilitar o questionamento de uma nova reflexividade na vida atual. O consumo e a comunicação, juntos, permitem diversas leituras do ponto de vista social e cultural que retratam um laço imenso de construção simbólica.

O cerne da reflexão do texto, amparado nas reflexões de autores como Massimo Canevacci e Rose de Melo Rocha, é destacar o papel fundante das interações entre culturas do consumo e culturas midiáticas na configuração da experiência urbana brasileira. No estudo, considera-se também todo o cenário construído para retratar o ambiente paradoxal citadino e o universo do consumo, incluindo os conceitos de cidade-mídia e corpos-mídia, que cada vez mais tecem e configuram processos e experiências comunicacionais da sociedade de consumo.

O capítulo a seguir, "Sequei $40 \mathrm{~kg}$ com a bala que emagrece: medicalização da comida em capas de revistas femininas", de Gesseldo de Brito Freire, Shirley Donizete Prado, Marcelo Ernandez Macedo, Maria Claudia da Veiga Soares Carvalho, Francisco Romão Ferreira e Claudia Olsieski da Cruz, mostra como os códigos culturais constroem sentidos às práticas alimentares no mundo moderno graças ao consumo, com base em artigos científicos e autores como Claude Fischler, Mabel Garcia Arnaiz, Marilena Chauí, Claude Lévi-Strauss, Michel Foucault, entre outros. O texto apresenta como a publicidade, numa economia capitalista, é responsável por vender subjetividades a públicos distintos.

A cada dia surgem mais plataformas para divulgação de produtos e o artigo refere-se ao recorte correspondente a revistas vendidas por preços reduzidos que expressam, em geral ao público feminino, representações e subjetividades que dialogam com o campo da alimentação, como são percebidas nas publicações da Editora Abril VIVA! Mais e Sou Mais Eu!, aqui tomadas para discussão. Especificamente as capas referentes ao ano de 2011 dessas duas revistas são os objetos do estudo, considerando o papel central da alimentação em suas narrativas habilmente construídas em alinhamento com o discurso científico, destacando-se as dietas e produtos para emagrecimento. "O novo pó que acaba com a fome" (VIVA! Mais, 2011, edição 595) é um dos muitos exemplos do jogo de palavras impresso nas capas em que a comida, os alimentos, os produtos industrializados, os nutrientes e medicamentos se igualam. É nesse cenário que surge a leitora- 
anunciante-mercadoria, uma pessoa comum e modelo da capa, estimulada a se promover em larga escala publicitária, sendo ao mesmo tempo promotora das mercadorias e as mercadorias que ela promove. Segundo os autores, "ser desejável, consumível, objeto de desejo do outro é o sonho possível: basta emagrecer..." faz parte do discurso de tais publicações e oferece ao leitor, imerso no drama cotidiano, um novo modelo de medicalização da sociedade por meio da comida.

Na sequência, o artigo "O corpo como mercadoria na sociedade de consumo: saúde ou estética?", escrito por Maria Luiza Martins Mendonça e Carlise Nascimento Borges, propõe uma discussão e uma reflexão sobre o controle do corpo, e também sua relação com os discursos da mídia, envolvendo conceitos de saúde, estética, especialmente entre as mulheres no processo de envelhecimento.

Seguindo as contribuições de Pierre Bourdieu e Marcel Mauss, entre outros, o artigo apresenta o poder simbólico trabalhado pela mídia que contribui sutilmente para a reprodução da ordem social. As narrativas apresentadas nos meios de comunicação de massa muitas vezes tendem para a imposição de um estilo de vida que padronizam não apenas produtos, mas também os corpos dos sujeitos que integram a sociedade de consumo. Entre as imagens e os discursos imperativos divulgados no espaço midiático, roteiros e conselhos espelham o corpo feminino a ser imitado.

Pesquisa realizada com 24 mulheres entre 45 e 60 anos, frequentadoras de academias de ginástica de Goiânia-GO, de diferentes classes sociais, ressaltou a relação entre saúde, estética e controle para um corpo perfeito. Os discursos enfatizaram como as mulheres se dedicam a alcançar uma imagem veiculada na mídia, demonstrando como as atrizes, apresentadoras e modelos se tornam referências a serem seguidas. Questões relacionadas ao controle e à disciplina foram constantemente percebidas nas respostas das pesquisadas, inclusive com ênfase nas práticas de consumo, que se apresentaram indissociáveis da busca por um estilo de vida saudável.

Um paradoxo se revela: a mesma mulher contemporânea que se liberta também se encarcera em regras, padrões, disciplina e autocontrole em seu cotidiano, e tais reflexões são corroboradas por autores como Michel Foucault e Gilles Deleuze. Manter o corpo jovem é ser um modelo de sucesso que se inscreve nas representações midiáticas, na construção do imaginário e, sobretudo, na subjetividade das mulheres. Entretanto, começa a haver uma quebra de paradigmas com as manifestações de resistência a tanto controle em busca da juventude, o que não significa uma rebelião contra o que as autoras chamam de "a ditadura da beleza”, mas já é um início de mudança para desfrutar e priorizar outros objetivos na vida.

"Impressões sobre o corpo feminino na interface mídia, consumo e ciência médico-estética: das imagens de papel à (i)materialidade do corpo simbólico" é o capítulo escrito por Camilla Araújo Lopes Vieira e Maria Lúcia Magalhães Bosi. No centro da análise está a interação entre mídia e ciência médico-estética na construção de referências estéticas, de beleza, estilos de vida, entre 
outras questões, como as que se referem ao poder e controle de estruturar e ajustar o corpo no tempo e no espaço, tendo como espaço de divulgação e visibilidade as revistas.

Michel Foucault, Paulo Ghiraldelli Junior, John B. Thompson, Sigmund Freud e Jacques Lacan são alguns autores presentes no artigo. O corpo, aqui enaltecido como o natural de hoje, é o que a mídia não cessa de valorizar, aquele que é trabalhado, tonificado, submetido a forte ação disciplinadora, que come o que é saudável, em contínua busca de aprimoramento estético e funcional. Para aderir à já gasta expressão qualidade de vida, o corpo também se submete a indústria da saúde e suas mais diversas tecnologias da vida. Segundo refletem as autoras, envelhecer está ultrapassado e estamos imersos em uma ordem de luta contra o sedentarismo e a velhice, em que o corpo é visto como máquina, organismo e, portanto, mais fácil de modelar.

Diante de um poderoso discurso médico-estético que vende produtos e serviços com o valor de saúde, a publicidade de informações e imagens em revistas comunicam a medicalização da vida, a partir de uma narrativa científica que serve como aliada na rede de subjetividades construída para atender ao apelo do consumo, que coloca o corpo como um revelador do lugar social, estilo de vida, gosto e comportamento do indivíduo a quem ele pertence.

O último texto desta primeira parte do livro, sobre as temáticas do Corpo, comunicação e estéticas contemporâneas, intitula-se "Cerveza de día, copa de noche: prácticas y discursos en la publicidad española de cervezas”, de Mabel Gracia-Arnaiz. Nesse capítulo, encontramos uma análise da publicidade de cervejas realizada na Espanha durante as últimas cinco décadas, com o objetivo de mostrar as mensagens produzidas pela indústria cervejeira para promover o consumo deste produto, que vem aumentando desde a década de 80, e estreitar o vínculo com seus consumidores. Integram este artigo as reflexões de Anthony Giddens, Roland Barthes, Kurt Spang e José Ramón Sanchez Guzman, entre outros.

Para a indústria de alimentos, a publicidade veiculada nos meios de comunicação de massa, ainda que cara, é muito rentável. Mais que uma prática comunicativa, ela informa as características do produto de maneira persuasiva, para promover sua necessidade material e simbólica de consumo, seu principal objetivo. Na escala de evolução do consumo de cerveja na Espanha, é preciso sinalizar que os espanhóis são mais produtores de cervejas que consumidores. Entretanto, com o investimento publicitário, o crescimento do consumo é notado, a barreira à entrada de cervejas estrangeiras é fortalecida, mas a restrição ao consumo de bebidas alcoólicas, a preferência por bebidas sem álcool e com baixo conteúdo calórico, a diminuição do turismo e a recessão econômica são algumas das razões para que, na década de 90, o consumo de cerveja comece a estancar e cair.

A consolidação do consumo de cerveja acontece quando a bebida passa a ser apresentada, ao final dos anos 80, como fundamentalmente "social", não somente para ser consumida nos meses mais quentes do ano, mas adequada para qualquer situação e em qualquer momento: na hora do almoço, como aperitivo, na saída à noite, celebrações e entre as comidas. Um dos títulos dos 
anúncios é um exemplo eloquente desta nova fase da bebida: "Cerveza de dia, Copa de noche". Ao largo dos últimos anos, os discursos publicitários apresentam a tendência de correlacionar temas como tradição, identidade, hedonismo e diferenciação e saúde, com o objetivo de vincular negócio e cultura, a fim de introduzir e manter as cervejas no cotidiano dos consumidores.

Dando início à segunda parte do livro, Comunicação, cidade e consumo, o capítulo "Darreceber-compartilhar: um ensaio sobre comunicação, sociabilidade e consumo entre jovens na cultura contemporânea", de Claudia Pereira, considera as trocas que se estabelecem nas redes sociais da internet, sobretudo entre os jovens, retomando, a partir da teoria de Marcel Mauss, a dinâmica social do "dar-receber-retribuir" na contemporaneidade e expandindo-a para outra forma, a do "dar-receber-compartilhar". Para esse estudo, como base empírica, serão usados dados primários coletados para uma pesquisa exploratória realizada durante um ano na rede social Facebook, através do Programa de Iniciação Científica do CNPq, com observações simples e participantes. Além disso, serão usados dados secundários de pesquisas como o Dossiê Universo Jovem MTV 5 - Screen Generation, entre outras.

Questões relacionadas à noção de juventude na contemporaneidade, o uso das novas tecnologias voltadas para a comunicação e prática da sociabilidade e o valor simbólico dos conteúdos compartilhados na dinâmica das redes sociais online estão presentes nesse ensaio. A autora também identifica categorias para descrever a intenção nas publicações no Facebook e os tipos de mensagens postadas. Segundo o Dossiê Universo Jovem 5 - MTV - Screen Generation, de 2010, entre os valores da juventude, a música possui valor simbólico importante e é como um bem de consumo na dinâmica da troca. O estudo discute os significados do "compartilhar" entre os jovens, o valor de uma vida social ativa, permanente e prestigiosa. As trocas simbólicas de dar, receber e compartilhar estabelecem uma ordem social, criando e mantendo hierarquias.

O texto que segue, "Políticas sociais de alimentação e nutrição: para além do biológico", de Susana Moreira Padrão e Luísa Ferreira da Silva, apresenta as políticas sociais como uma função do Estado para a proteção à saúde e abre uma discussão sobre seus papéis no âmbito da alimentação e nutrição, nos cenários do Brasil e de Portugal, no que se refere à alimentação saudável. O debate propõe uma reflexão para além do biológico e do condicionamento a uma série de restrições e deveres, ampliando a percepção dos significados e sentidos da comida e da alimentação no cotidiano, com o apoio de artigos científicos e autores como Pierre Bourdieu, Luciano Gruppi, Ana Maria Canesqui, Rosa Wanda Diez Garcia, Michel Foucault e Claude Lévi-Strauss, entre outros.

O capítulo se dedica a pensar sobre o papel do Estado como promotor de políticas sociais e apresenta uma análise crítica das políticas de promoção de saúde, em especial ao "estilo de vida saudável” preconizado pelas políticas de promoção de alimentação saudável. Essas políticas resumem-se a ações educativas dirigidas a diferentes grupos da população que seguem o paradigma biológico hegemônico na concepção da nutrição, limitando-se aos nutrientes e seus efeitos no 
organismo, sem espaços para as identidades sociais da coletividade e sem considerar a comida e o comer como fenômeno social - por isso, são ineficazes na transformação de atitudes e práticas do cotidiano. É nesse momento que as autoras trabalham a questão das racionalidades leigas, com base em material empírico de pesquisa desenvolvida em Portugal, que resiste à verdade das evidências científicas, em clara demonstração da necessidade de ampliar o olhar sobre o comer, a alimentação e a comida, incorporando os aspectos subjetivos, simbólicos inerentes à cultura das sociedades e suas identidades, além dos contextos sociais, econômicos e seus determinantes.

"Eu sou a melhor cidade entre as cidades: reinventando a imagem do Rio de Janeiro", de Vania Oliveira Fortuna, trata da questão de a Cidade Maravilhosa reinventar sua imagem por meio de seus sentidos múltiplos, intensos e por vezes até contraditórios, para destacar-se no cenário mundial das grandes metrópoles. No desenvolvimento do artigo, destacam-se as reflexões de Jean Baudrillard, Walter Benjamin, Beatriz Jaguaribe e Georg Simmel, entre outros.

Os investimentos bilionários dos megaeventos na cidade são molas propulsoras para a construção de representações e imaginários, através de narrativas e discursos que imprimem, no cotidiano do Rio de Janeiro, uma nova ordem urbana - a consagração de cidade-marca. Toda uma dinâmica que faz parte do processo de branding pelo qual o Rio está passando e que envolve a criação de imagens para serem consumidas no espaço da cidade e da mídia, construindo o que se quer vender. Os megaeventos do Rio de Janeiro produzem novos sentidos e novas formas de perceber e experimentar o espaço urbano. Também promovem a formação de novas identidades e são essenciais ao consumo da cidade.

O capítulo seguinte, de autoria de Antonio Luiz de Medina Filho e Kerolly Dias Duarte Motta, é "Cidade, consumo conveniente, paradigma científico e marketing”, e traz em suas páginas, com o suporte de teóricos como Jesús Contreras, Mabel Gracia, Thomas Kuhn, Bruno Latour e Serge Moscovici, entre outros, a reflexão sobre como a escassez de espaço, tempo e atenção teve grande significado nas alterações dos modos cotidianos de viver e conviver na cidade, especialmente nos hábitos alimentares, que, sofrendo os impactos da efervescência da metrópole, incorporaram o valor da "conveniência" no comportamento do consumidor, acelerando o tempo de produção e de consumo dos alimentos. Esta tendência é crescente, e a indústria e o comércio da alimentação já promoveram diversas transformações com o apoio de estratégias de marketing com base nas informações "científicas" divulgadas na mídia e inscritas nos produtos alimentícios, de forma a gerar altos lucros.

Os discursos da ciência e o campo da alimentação apresentam vulnerabilidades no próprio processo de construção do saber científico e são discutidos nesse capítulo. O nutricionismo obscurece diversas dimensões da realidade ao focar somente nos nutrientes. Ainda mais grave é quando as mídias se apropriam dos resultados de pesquisas científicas e promovem sua divulgação sem uma revisão dos métodos e resultados para hábil produção de subjetividades e modulando representações 
a favor de interesses comerciais. As estratégias de marketing dos produtos alimentícios procuram atuar nos níveis da razão, emoção e do instinto para alcançar o consumidor, levando-o à ilusão de que um alimento artificialmente produzido industrialmente é superior ao alimento integral e orgânico. Tudo a favor da conveniência.

O capítulo que encerra a segunda parte do livro aborda o tema "Rock in Rio como plataforma transmídia: consumo de um megaevento convertido em caso de amor”, de Ricardo Ferreira Freitas, Flávio Lins e Maria Helena Carmo dos Santos. A partir do estudo de caso do Rock in Rio, é possível perceber como os megaeventos, inscritos no cotidiano das cidades, criam plataformas comunicacionais através de recursos transmídias que possibilitam experiências multissensoriais com seu público. TVs, smartphones, games, entre outras plataformas comunicacionais, possibilitam o contínuo contato com seus consumidores através da veiculação de informações e alimentam uma rede de consumo de produtos e serviços. A emoção não começa com a compra do ingresso e o término do espetáculo, mas meses antes e depois do megaevento.

Nesse artigo, encontramos as reflexões de autores como Georg Simmel, Zygmunt Bauman, Guy Debord, Henry Jenkins e Michel Maffesoli, entre outros, além de depoimentos do idealizador do festival, que embasam as questões pertinentes à relação de consumo e entretenimento, dos megaespectáculos, e o desejo de estar junto e como a marca Rock in Rio se converteu em uma lovemark, que é mais poderosa que a marca tradicional por conquistar o "amor" e o "respeito" de seus consumidores. O slogan "Por um mundo melhor", somado à marca a partir do terceiro festival, conferiu ainda mais visibilidade a seus produtos, gerou potenciais lucros e motivou o consumo de lazer e entretenimento. O prazer e a satisfação em participar desse megaevento aposta na felicidade e revela a emoção de estar junto com afetividade num espaço repleto de possibilidades e experiências multissensoriais.

O capítulo "Galeria River: sociabilidade e consumo cultural no Rio de Janeiro" introduz a terceira e última parte do livro, que aborda as temáticas Comunicação, consumo e cultura. O texto escrito por Cíntia Sanmartin Fernandes parte da premissa de que, nas cidades interculturais, as narrativas estão em constante construção, reinventando-se através das relações com os outros. Nesse cenário, é possível perceber que a cidade aqui é tratada como espaço comunicacionalinteracional, sensível, afetivo, vivificado nas dinâmicas socioculturais e ambientais comunicantes de diversas identidades, significações, entre outras, em que corpo e ambiente interagem configurando outros significados que transformam os locais em lugares. O capítulo objetiva a possibilidade do deslocamento da compreensão social para além da funcionalidade e das fixações identitárias, sugerindo constante movimento de experiências entre sujeitos.

Para analisar as práticas de consumo nesse contexto, elegeu-se o Arpoador e mais precisamente a Galeria River, na divisa entre as Praias de Copacabana e de Ipanema, onde o cotidiano acontece na interação de distintos grupos, sendo um lugar de enunciação de múltiplos códigos identitários 
conversando entre os aspectos globais e locais na dimensão entre os corredores da galeria e a calçada. O artigo conta com teóricos como Néstor Canclini, Lucrécia D’Alessio Ferrara, Michel de Certeau, Walter Benjamin e Michel Maffesoli, entre outros, e está ancorado em uma pesquisa da autora sobre as galerias de passagens e/ou as ruas galerias da cidade. Contextualiza a importância desses espaços no cotidiano da vida citadina, em que o consumo aparece como prática de reconhecimento cultural, de identidade individual ou coletiva. Ao longo do texto, depoimentos de quem é proprietário ou trabalha em lojas da galeria dão o tom ao artigo e percebe-se que é possível manter uma unidade de identidade dos diversos grupos, ao mesmo tempo em que se promove o intercâmbio de valores e das práticas identitárias abertas a outras possibilidades culturais.

O artigo a seguir, intitulado "Quando o Túnel Rebouças é o limite: sentidos da relação entre a zona sul e a zona norte do Rio de Janeiro", de Mônica Christina Pereira de Sousa, parte do ano de 1984, quando os novos trajetos dos ônibus com as linhas 460 (São Cristóvão/Leblon) e 461 (São Cristóvão/Ipanema) através do Túnel Rebouças integravam a zona sul e a zona norte com menos tempo de travessia e mais benefícios aos trabalhadores usuários desse meio de transporte. Com a estação do verão e a possibilidade do lazer da praia mais requisitado, as linhas passaram a circular aos finais de semana e as disputas por distinção nos territórios da zona sul, especialmente entre os nobres de Ipanema e os "farofeiros" do subúrbio, se acirraram. O texto relembra o movimento dos estudantes da Universidade Federal do Rio de Janeiro para defender os direitos dos suburbanos irem à praia, a cicatriz deixada no cenário zona sul pelo arrastão e a proposta de "piscinões" em Cieps nos subúrbios.

O consumo na fetichização do espaço-sujeito, ancorado nas reflexões de Karl Marx, Max Weber, Pierre Bourdieu e Mary Douglas, é sublinhado no artigo num processo de luta pelos sentidos e significados dos lugares e dos capitais dos sujeitos pertencentes a eles. O texto revela uma cidade de conflitos socioespaciais, simbólicos, que demarca divisões de poder, de dominação e de violência simbólica, que retratam a lógica cruel dos espaços da urbe que emanam uma atroz homogenia.

O capítulo seguinte, "Quando o dinheiro se transforma em mercadoria”, de Viviane Marinho Fernandes, nos leva a refletir sobre o impulso, a emoção e a satisfação presentes na compra a partir dos discursos publicitários. Especificamente, quando o foco é o uso dos cartões de crédito, não há menção a juros ou taxas, questões financeiras ou burocráticas. Os sentidos das mensagens que incentivam o uso dos cartões destacam a liberdade e o acesso ao consumo, o desfrute do mundo com experiências únicas de forma mais segura, com mobilidade para que os usuários possam agir conforme seus desejos e necessidades. O estudo está atento a examinar e destacar os sentidos sociais e culturais atribuídos às moedas, especialmente como as ferramentas financeiras são apresentadas às pessoas, utilizando a publicidade como janela de observação dos processos de marcação e distinção dos meios de pagamento. Para uma discussão mais ampla, a autora tem o apoio das pesquisas de Viviana Zelizer, que iluminam as interseções entre dinheiro e relacionamentos, 
ressaltando a importância do afeto, dos gêneros ou da idade na esfera econômica. Conta também com o suporte teórico de autores como Mike Featherstone, Patrick Charaudeau, Georg Simmel, Nigel Dodd, entre outros.

O foco do estudo são as estratégias de comunicação apresentadas pelas empresas Visa e Mastercard, os conceitos atribuídos a segurança, controle e conveniência, que são fortemente adotados nos discursos que valorizam o uso dos cartões sobre outras formas de pagamento. Embora os filmes dessas empresas retratem a transação comercial oferecendo soluções de pagamento, os discursos publicitários neles divulgados apoiam-se nos afetos, e as relações familiares associadas às transações comerciais são constantemente enfatizadas. A linguagem destacada pela economia não é a de que se faz uso na promoção dos cartões, mas a do campo semântico que se refere às emoções e experiências, observando-se o emprego de verbos como "curtir", "aproveitar", "compartilhar", entre outros. O que está em jogo é estreitar vínculos afetivos e fortalecê-los através do consumo de bens e serviços por intermédio dos cartões.

O texto apresentado na sequência é "A redenção moral pelo consumo: ética, comunicação e o consumo consciente", de Luiz Peres Neto. Três questões dão início ao capítulo: "Existem valores morais inerentes às práticas de consumo? Há um consumo bom? Se há um consumo consciente, podemos falar de outro tipo de consumo, que seja sua antítese?” (p. 231). Nas dimensões simbólica e material, social e de produção, podemos pensar o consumo e refletir sobre as ações do homem na vida em sociedade, perceber sua inscrição em certas culturas, a comunicação de seus valores, identidades e pertencimentos. Discursos morais antimaterialistas atribuem sentidos negativos ao consumo. Por outro lado, as práticas do consumo são boas para a economia porque tornam possível o funcionamento da sociedade a partir do atendimento das necessidades dos sujeitos.

No conflito entre consumo bom ou ruim, e percorrendo caminhos muitas vezes contraditórios, com base nas reflexões de Friedrich Nietzsche, Luis Alonso, Daniel Miller, Danilo Marcondes, Néstor Canclini, Maria Aparecida Baccega, entre outros expressivos teóricos, observa-se a moral iluminando a discussão sobre as chamadas "práticas de consumo consciente", pertinentes aos consumos responsável, ético e sustentável, que delegam ao indivíduo a responsabilidade pela felicidade da sociedade por intermédio de suas escolhas, e a consolidação de questões referentes à sustentabilidade, rearticulando o consumo a partir de aspectos éticos e ambientais.

O debate sobre ética e consumo e o conceito de consumo consciente são destacados nesse capítulo e apontam como comunicação e consumo estão inter-relacionados. A mídia e a publicidade são chaves no circuito produção-consumo. Os discursos midiáticos são de grande importância na forma como os sujeitos repensam suas ações no cotidiano e como negociam a atribuição de valores morais ao agir. Problematizar as inter-relações entre ética, consumo e comunicação se faz importante. Num mundo em que as práticas de consumo são fundadas eticamente em "positivas" ou "negativas", consumo responsável, sustentável ou ético tornaram-se variações de uma "redenção 
moral" por meio de um cosumo considerado positivo, com base na "ilusa" tese de que a partir da mudança nos hábitos de consumo modificaremos a sociedade.

"Paraíso Tropical: a difusão da cultura de consumo nas telenovelas brasileiras", de Vanda Gomes e Daniele Fortuna, é o capítulo seguinte e propõe um questionamento sobre a relação entre telenovela, cultura de consumo, midiatização e estilos de vida. Com o apoio teórico das referências culturais de Jesús Martín-Barbero, são analisadas as características das telenovelas e os estilos de vida construídos a partir delas. O estudo de caso feito com a novela Paraíso Tropical, exibida pela Rede Globo em 2007, de autoria de Gilberto Braga e Ricardo Linhares, encerra o capítulo. Através desse artigo, conclui-se que as telenovelas difundem a cultura de consumo por intermédio da midiatização, que pode ser entendida como a influência da mídia sobre a sociedade, tornando possível influenciar a identidade e a construção de estilos de vida.

A questão da cultura de consumo, midiatização e identidade, a formação dos estilos de vida, intimamente interligadas, é trabalhada neste capítulo, a partir das reflexões de Don Slater, Anthony Giddens e Mike Featherstone, entre outros autores. Ao longo do artigo, são debatidos o fenômeno, chamado por Stig Hjarvard e Muniz Sodré, de midiatização, responsável pela disseminação da cultura de consumo que passou a impactar a identidade, hoje apresentada de várias formas móveis denominadas por Stuart Hall de "estilos de vidas", e as telenovelas como produto midiático que contribui para a difusão da cultura de consumo e formação dos estilos de vida. Através desse capítulo, conclui-se que midiatização, cultura de consumo e cultura contemporânea se retroalimentam, oferecendo conteúdo umas às outras, e esta relação, somada à identidade, pode ter uma microrrepresentação através da análise das telenovelas e sua influência na formação identitária.

O capítulo que encerra o segundo volume da Série Sabor Metrópole aborda uma questão crescente, que é a do jovem do campo que abandona o meio rural em busca de melhores condições de vida no espaço urbano. "A juventude do campo na cidade: considerações sobre ideologia, consumo e construção de identidade”, de Larissa Escarce Bento Wollz e Francisco Romão Ferreira, retrata essa migração e sua ligação com a construção de uma nova identidade social para o jovem camponês que se lança no mundo das possibilidades que é a cidade. $O$ texto faz parte da pesquisa da tese de doutorado Percepcões de infância e juventude no/do campo e apresenta uma reflexão sobre o tema e questões e ele associadas, como as da desigualdade social no Brasil, juventude no campo, produção de subjetividade e a construção da identidade social entre jovens, a partir das reflexões de autores como Anthony Giddens, Zygmunt Bauman, Pierre Bourdieu, Néstor Canclini e Karl Marx.

No artigo é traçado um panorama do campo e juventude no Brasil, sublinhando que o acesso à escolaridade e à qualificação profissional é a principal questão para os jovens camponeses. É, portanto, a motivação para romper com as formas tradicionais de pensar, buscar informações e disputar bens simbólicos e capital cultural necessário para ingressar na "sociedade do 
conhecimento" que sustenta o capitalismo global. Não se trata apenas de inserir o jovem no mercado de trabalho, mas oferecer, sobretudo, uma formação cidadã e democrática, para retirálo da situação de pobreza social, intelectual e existencial. "Juventude do campo: identidade e globalização" é um ponto presente e ressalta que a construção da identidade do jovem do campo ou da cidade incorpora tendências e questões individuais e sociais, referências locais e globais, agrupa influências do mundo globalizado e disposições pessoais com a ampliação dos canais de acesso à informação, a produção e o consumo de artefatos da indústria cultural e o suporte dos meios de comunicação de massa, que são produtores de informações e disseminadores de comportamentos nos lugares mais distantes. Juventude, identidade e ideologia são questões que fomentam a discussão sobre a compreensão dos processos ideológicos de construção da identidade, produção de subjetividades e acesso à informação e à escolaridade que estão sendo oferecidos aos jovens do campo, influenciados pela ideologia dominante de narcisismo e consumo que pode aprisioná-los, mesmo que sendo libertos pela possibilidade de informação e conhecimento. Compreender esse processo histórico e buscar alternativas mais dignas para o jovem no/do campo, no sentido de acordar sua consciência crítica e ajudá-lo a se libertar de condições sociais julgadas injustas, são fundamentais a partir da análise da questão da construção da identidade deste grupo social em relação à indústria cultural e ao consumo.

As reflexões sobre a lógica do consumo e sua influência na construção dos múltiplos sentidos do corpo na complexidade da metrópole, a partir dos olhares dos autores presentes nos 16 capítulos do livro Corpo e Consumo nas Cidades, ampliam a discussão sobre temas indispensáveis ao nosso viver contemporâneo no espaço urbano e transitam entre a comunicação, o consumo e o corpo. Esta segunda obra da Série Sabor Metrópole promove uma leitura agradável e que alimenta os apetites cotidianos, cada vez mais naturalizados e inscritos nos corpos, nas formas de consumo dos citadinos e nas diferentes sociabilidades. São jogos de poder que reafirmam continuamente a construção e a reconstrução identitária de vidas imersas no mundo material e simbólico das urbes.

Por todo o valor dessa publicação, que apresenta em suas páginas a articulação da UERJ com pesquisadores de instituições e universidades de renome, não só do Brasil, mas também da Espanha e Portugal, recomendo sua leitura atenta. As importantes contribuições presentes nessa obra são destinadas a professores das grandes áreas da Comunicação e da Alimentação e Nutrição, alunos e pesquisadores interessados em ampliar seus conhecimentos nos campos das Humanidades e das Ciências da Saúde. 
